\title{
Engine idle speed control research status and development trend
}

\author{
Yin Fengfeng ${ }^{1, a}$, Sun Jianmin ${ }^{2, b}$ and Wang Wenwen ${ }^{3, c}$ \\ ${ }^{1}$ School of Mechanical-electronic and Automobile Engineering, Beijing University of Civil \\ Engineering and Architecture, China \\ ${ }^{2}$ School of Mechanical-electronic and Automobile Engineering, Beijing University of Civil \\ Engineering and Architecture, China \\ ${ }^{3}$ School of Mechanical-electronic and Automobile Engineering, Beijing University of Civil \\ Engineering and Architecture, China \\ ajinmin sun@tum.com, bm17888812565@163.com, c18810969926@163.com
}

Keywords: Engine, idle speed system, control algorithm, method evaluation

\begin{abstract}
The engine idle speed control is one of the most important challenges in the engine control fields, essentially the engine idle speed control is a nonlinear, time-varying, complex and uncertain dynamics control problem, the present study the idle speed control problem for improve the gasoline engine fuel economy and reduce emissions is of great significance, this paper reviews the current various working condition of the engine idle speed control method, including the now widespread use of classical control, modern control and intelligent control, the control method can also be used in automobile, electronic, mechanical, and other control system.
\end{abstract}

\section{Introduction}

Idle condition is one of the main working condition of the engine.From the Olympic Games in Beijing in 2008, advocating the green Olympic Games and the blue Olympic, to the APEC meeting in November 2014, Beijing, tianjin and hebei province implement the APEC blue.According to statistics, China has sold 23.4919 million cars in 2014 according to statistics, ranked first in the world for sixth consecutive years. When the car drived in traffic density of roads, about $30 \%$ of the fuel consumption in idling process.In car gasoline-fuelled vehicles emission test, idle amount of $\mathrm{CO}$ and $\mathrm{HC}$ emissions are usually accounted for about $70 \%$ of the total emissions. The idle speed will increase fuel consumption, causing unnecessary waste when it is is too high, While the idle speed is too low to make obvious reinforcement effect of exhaust gas dilution of mixture in cylinder, if a slight change of load or resistance will cause instability or even shut down engine operation.Therefore, in order to meet the requirements of increasingly stringent emission regulations, as far as possible,we should reduce the idle speed and maintain the stability of idle speed appears especially important.But the engine idle speed control system is the most important in the electronic control system and it is also one of the most complicated part, researchers have a lot of research on the idle speed control around the world, however, its performance is still not satisfactory.

\section{Engine Idle Speed Control Strategy}

\subsection{The Idle Speed PID Control}

Currently most of the control strategy is to adjust air amount proportional integral (PI) control and ignition proportional feedback control in the idle speed control.PID control is one of the most basic control algorithm in industrial control, due to its advantages of simple, reliable and has been widely used.The car is still widely used PID control. PID fuzzy controller consists of The PID and fuzzy control.Idle speed PID control is a kind of reliable control method in the system without complex, but there is no general rule to adjust the three parameters of PID and need according to the experience of the experts.PID controller has been conducted on ford $1.8 \mathrm{~L}$ engine experiment, it optimize 
performance index by adjusting the controller parameters. PID idle speed control system block diagram as shown in Fig. 1. PID controller is a linear controller, according to the given value $r(t)$ and the actual output value y $(\mathrm{t})$ to control deviation e $(\mathrm{t})$ control, conventional PID control algorithm:

$$
u(k)=k_{p} e(\mathrm{t})+k_{i} T \int_{0}^{t} e(t) d t+k_{d} \frac{d e(t)}{d t}
$$

$u(k)$ for idle speed control of the actuator, $\mathrm{Kp}, \mathrm{Ki}, \mathrm{Kd}$ are respectively proportion coefficient, integral and differential coefficient.

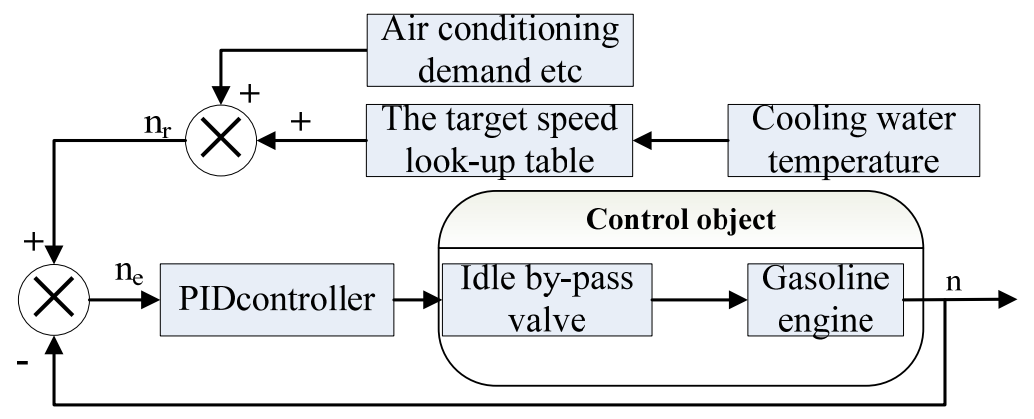

Fig. 1 PID idle speed control system block diagram

In [1], it designed variable parameter PID control system and fuzzy control system for idle condition respectively, and has carried on the real vehicle experiment contrast.The PID control method has carried on the experiment on fukang car, the results show that under the condition of no load plus or minus 50 RPM speed fluctuations.Fuzzy control method in fukang cars has carried on the experiment, the results show that under the condition of no load + 25 RPM speed fluctuations.In [2], for the research of geely MR479Q four-cylinder four-stroke gasoline engine, the incremental digital PID idle speed control is given for self-developed engine management system (EMS) of the concrete implementation plan, through the bench test engineering setting method was used to its control parameters setting, optimizing system step response characteristics. The digital PID idle speed control system after setting has step response speed, small overshoot, reasonable steady-state error and the mutation load has strong ability to adapt, the maximum overshoot within the plus or minus $50 \mathrm{r} / \mathrm{min}$, $10 \sim 15 \mathrm{~s}$ stable time, steady-state error within the plus or minus $20 \mathrm{r} / \mathrm{min}$, basic meet the requirements of gasoline engine idle speed control system. $\operatorname{In}[3]$, the PID control algorithm is successfully applied to the 462Q gasoline engine electronic control system, through the online adjust the parameters, obtained good control effect and high speed control precision.

\subsection{Idle Speed Fuzzy Control}

Fuzzy control use human language information, simulate human thinking.it is easy to accept,design simple and has strong anti-jamming capability.Idle speed fuzzy control is the first successful application to the idle speed control system of artificial intelligence methods.Fuzzy controller based on fuzzy information the control rules, fuzzy controller input speed variation, speed deviation change rate in improving the system characteristics, by acting on the stepper motor PWM signal as the output variable, direct control of the car engine speed.At the same time, the idle speed compared with idle speed target through feedback, to draw speed deviation and the rate of change of rotation speed deviation.Fuzzy controller with two input through fuzzification, fuzzy inference and to blur the process can output the stepper motor control signals, so that the actual speed fast approaching target speed.In order to avoid the engine stalling and switch engine vibration caused by air conditioning, a fuzzy PID controller has been applied to the 1.3 L PFI engine of the plane.Speed fluctuation is reduced a lot.Under variable load working condition of idle speed, the fuzzy control system has shorter transition time than the PID control system, small volatility.Simple and practical fuzzy control technology have do not rely on accurate mathematical model and it is not sensitive to system parameter and interference etc, its characteristic is especially suitable for complicated nonlinear time-varying parameter system, and therefore will be more widely applied in the field of motor control.But Fuzzy control need experience, its overall performance has yet to be tested when it 
compared with other idle speed control method.The structure of fuzzy controller of idle speed control system block diagram is shown in Fig. 2.

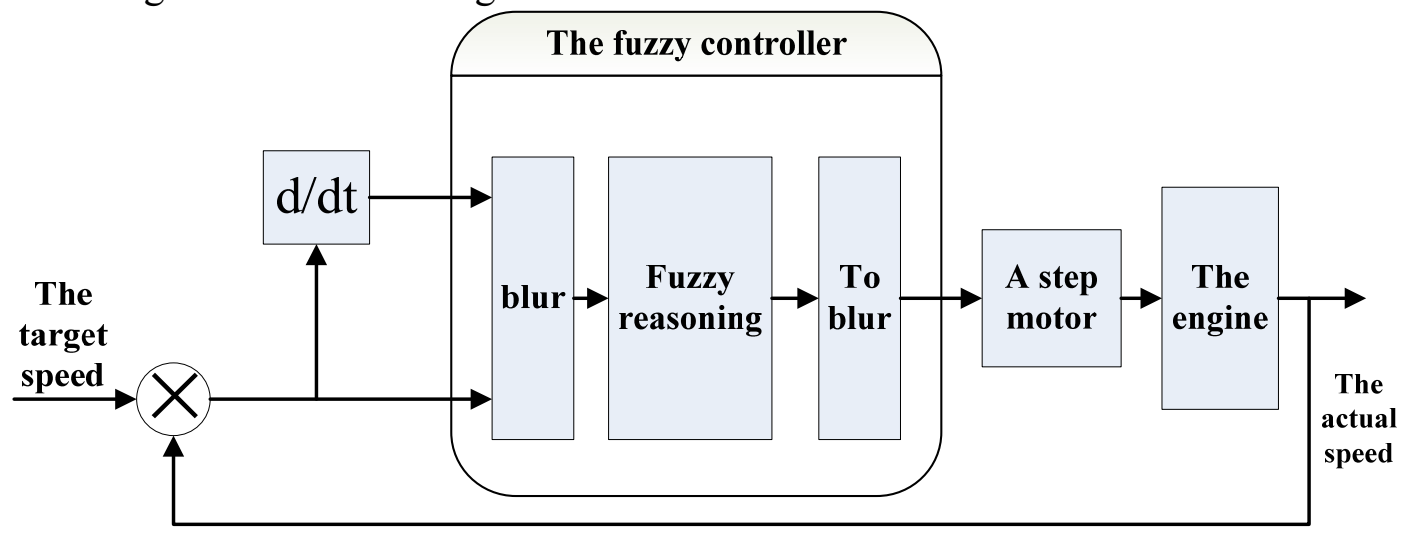

Fig. 2 Idle speed fuzzy control system

Fuzzy control technology has been widely used in automotive engineering in foreign countries. $\operatorname{In}[4]$,it adopts fuzzy PID control method, and it applies on the 1.6L turbocharged diesel engine, mainly considering two factors affecting the ignition timing and fuel injection quantity, the designe of fuzzy controller use the irregular membership functions, the controller reflects the good robustness.In [5], it lists the idle speed control problem of a few solutions, including PID control and fuzzy logic control, adaptive fuzzy logic control and dynamic matrix control.All of the controller by simulation are compared, and tested in real vehicle.Finally, mean square error (mse) and the maximum error of performance have been evaluated, the results show that the idle speed control of the car, several advanced control method can replace the existing of PID control.Some domestic research apply fuzzy control to the engine fuel injection and ignition, idle speed control.Many researchers put forward using fuzzy logic control method to realize the engine idle speed control.In[6], considering the working process of engine idle speed nonlinear, time-varying and uncertainty, fuzzy control theory is studied in the application of the engine idle speed control.We design a gasoline engine idle speed fuzzy control system and provided by the MATLAB Simulink simulation tool to determine the parameters of the control system. The results show that the fuzzy control method for the stability of the engine idle speed control is feasible and effective, good control effect, good dynamic and static performance, strong robustness, theoretically it solved the problems of engine idle speed controi and have laid a good foundation for further practical application.

\subsection{The Idle Speed Adaptive Control}

Adaptive controller can modify their own characteristics to adapt to changes in the object and the dynamic characteristic of disturbance.Adaptive control of the research object is the uncertainty of the system to a certain extent, this so-called "uncertainty" refers to describe the mathematical model of controlled object and its environment is not entirely sure, including some unknown factors and random factors.Any actual system has a different degree of uncertainty, these uncertainties are sometimes performed within the system, sometimes on the outside of the system.From within the system, a designer in advance is not necessarily to know for sure to describe the structure and parameters of the mathematical model of controlled object,.As the influence of external environment on the system, they can be equivalent to many disturbances.These disturbances are often unpredictable and they might be deterministic, such as constant load disturbance, the amplitude and the time is unpredictable and can be random, such as waves and wind disturbance.In addition, there are some measurement noise from different measuring feedback loop into the system. The statistical characteristics of random disturbance and noise is often unknown, in the face of the objective existence of all kinds of uncertainty, how to design the appropriate control action and make a specific performance indicators to achieve and maintain optimal or approximate optimal, this is the adaptive control problem study.In recent years, some scholars try to apply adaptive controller with the car engine idle in the system.Idle speed adaptive control model as shown in Fig. 3. 


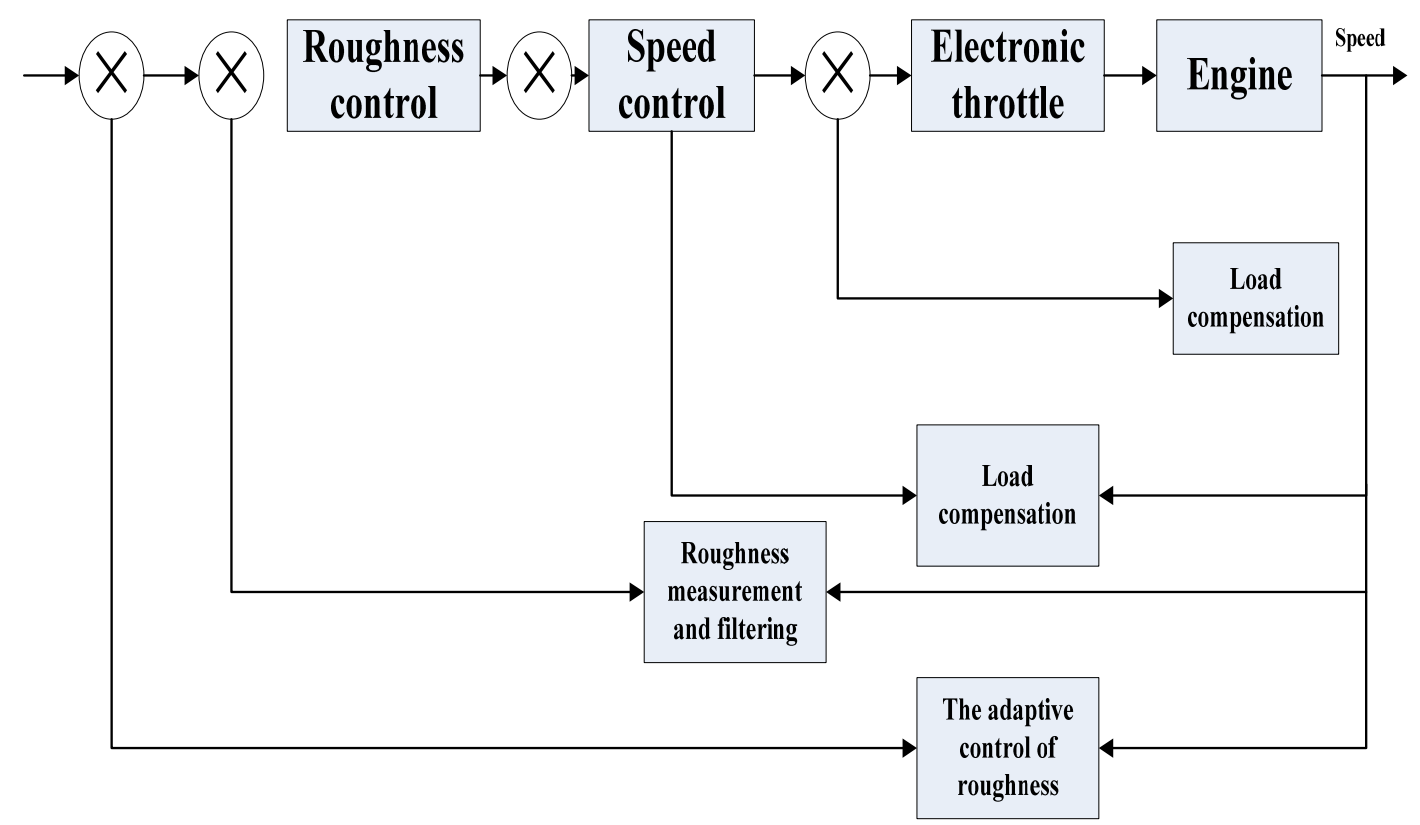

Fig. 3 Idle speed adaptive control model

In [7], two controller was designed, an adaptive feedforward controller (AFFC) and adaptive controller (APC) were tested in an actual vehicle.AFFC proved by experiments is a simple feedforward as the core and show a better reference tracking and anti-interference ability in the simulation and experiments. The APC is a complex adaptive controller, it is a kind of feedforward and feedback paths and adaptive control method based on time-delay systems.In[8],it adopted a kind of adaptive kalman filter based on torque compensator engine idle speed control system and adopts the adaptive kalman filter for PID idle speed control system for torque compensation, it has good anti-jamming capability and faster response speed, and through and PI, the experimental results of PID controller to verify the validity of the method.

\section{The Development Trend of Engine Idle Speed Control System}

From the research status of idle speed control in recent years, as you can see the emphasis for the study of the domestic and foreign automobile engine idle speed control has been from the traditional PID control based on parameter control without precise model, expert system which is not sensitive to environment and the controlled object parameters, based on the observer's control, fuzzy control, neural network control, sliding mode control, optimal control direction.But it is not to say that the nonlinear control system can achieve satisfactory control results, in [9], the author on the nonlinear engine idle speed control problem use the linear quadratic regulator (LQR), the classic PID control, fuzzy control and sliding mode controller has carried on the detailed comparative experiments.Actual results are disappointing, the control effect of two kinds of nonlinear control method after inferior to before two kinds of traditional linear control method, not to mention the complex, long-term operation of the engine idle speed stability problems. The Car in the process of running state changes very quickly,it has a signal transmission between each physical parts, coupled with each other, making car should have high real-time control algorithm, the computing speed of the controller as quickly as possible. However,the car has strong nonlinear,it has brought the huge challenge for the algorithm of vehicle control hardware design. The actual engineering design mainly by the logic threshold method and PID plus map feedforward method is given priority to, other senior algorithm is not perfect from the design of the model to the algorithm itself, a lot of algorithms is restricted by the accuracy in the implementation process, feasibility and complexity, it has some limitations. Therefore, how to make use of nonlinear control theory and algorithm to simplify, integration of online control methods is a trend for the future development of motor control. 


\section{Summary}

Because car operation condition is very complex, and changes frequently.Car often is in idle condition in the numerous urban traffic congestion, a considerable portion of the fuel consumption of the about on this. So improving the engine has great effect on economic performance in the engine idle speed control.Completely the power of the engine is not used to drive a car, the idle task make the engine idling away, rather than isothermal.Idle consumption of fuel is used to completely overcome the friction, in order to reduce the friction work to save fuel.The speed in idle is the lower the better.But if the idle speed is lower, exhaust gas dilution effect is more obvious, it must supply a strong mixture, the result is incomplete combustion, $\mathrm{HC}$ and $\mathrm{CO}$ emissions increase.This is an important significance in idle speed control. So, for effective control of idle speed for improving vehicle fuel economy, improving the vehicle ride comfort and reducing emissions have great significance. Idle Car engine idle speed control strategies are reviewed, the choice of idle speed control method in all aspects of the idle speed control performance plays an important role, such as the stability of idle speed, fuel economy and emissions, etc.In this paper, control methods including classical control, modern control and intelligent control.After these idle speed control method could also be used in hybrid cars, the car idle speed control on the complex engineering problems provides a typical example of diversifying preface and control method, the control method of automobile, electronics, machinery, aviation and challenging in the field of research provides the help.

\section{References}

[1] FanLin pu-cheng pei, Yang wu, ShenLin zheng-mao ye. Electronic control gasoline engine idle speed control method [J]. Journal of automobile engineering. 2002:490-493

[2] Dong-wei yao, yuhai wang, zhi-jia Yang, yuan guang-jie. The speed of engine based on the incremental digital PID control research [J]. Journal of zhejiang university, 2010, 44 (6) : 1122 1126

[3] Huang Ying, Zhang Fujun. Gasoline Engine Idle Speed Control System Development Based on PID Algotithm[J]. Beijing Institute of Technology, 2000,35 47

[4] Kamyar Nikzadfar, Alireza Noorpoor,Amir. H. Shamekhi.Design of an optimal idle speed controller for a turbocharged diesel engine using fuzzy logic method[J]. Journal of Mechanical Science and Technology. 2012: 2325-2336

[5] Thornhill , S. Thompson , H. Sindano. A comparison of idle speed control schemes [J]. Control Engineering Practice.2000:519 530

[6] Zhang Cuiping, Yang Qingfou,Han Yilun. The stability of the gasoline engine idle speed fuzzy control simulation [J]. Journal of internal combustion engine engineering. 2003:38-41

[7] DaeEun Kima, Jaehong Park .Application of adaptive control to the fluctuation of engine speed at idle[J]. Information Sciences. 2007:3341-3355

[8]KOLMANOVSKY I,DEUR J. Adaptive Kalman filter based load torque compensator for improved SI engine idle speed control[J]. IEEE.Transactions on control system technology.2009:98-110

[9] Kjergaard L, Nielsen S, Vesterholm T and Hendricks E. Advanced nonlinear engine idle speed control Systems[D]. SAE paper No.940974.1994 